\title{
Grillparzers Zeit
}

\section{Paul Hoffmann}

Die Wiederkehr von Grillparzers 200. Geburtstag in diesem Jahr hat das allgemeine Bewußtsein in Deutschland kaum tangiert. Im Feuilleton deutscher Zeitungen waren die obligaten Gedenkartikel erschienen, journalistische Routine zumeist, die im Klischee und der Anekdote stecken blieb.

Der 15. Jänner, Grillparzers Geburtstag, war der Tag, an dem das Ultimatum auslief, und die Welt bangte den Nachrichten entgegen. Doch das war wohl nicht der Grund, daß das Kulturprogramm der deutschen Rundfunk- und Fernsehanstalten sich zu Grillparzer - aus gegebenem Anlaß - so wenig einfallen ließ. Immerhin das Zweite Deutsche Fernsehen brachte im Spätprogramm Die Jüdin von Toledo, in der Salzburger Festspielinszenierung Thomas Langhoffs, des illustren DDRRegisseurs. Die geglückte Filmaufzeichnung einer überzeugenden, eindrucksvollen Aufführung. Das Lob der Salzburger Premierenkritik war, so weit ich sehe, einhellig gewesen. 'Endlich wieder großes Theater', hieß es. Man schien überrascht. Als hätte man erst jetzt Grillparzer entdeckt. Auch Langhoff hatte ihn ja vorher nicht gelesen. Anläßlich der Wiener Neuinszenierung von Libussa schrieb jüngst der Theaterkritiker $\mathrm{H}$. H. Hahnl, diesmal ein wirklicher Grillparzerkenner: "Es scheint, als lockte dieses besonders 'sperrige' GrillparzerStück nach jahrzehntelanger Grillparzer-Verachtung wieder Regisseure. Im Griff haben sie ihn noch nicht."1 Dennoch bleibt auch das bemerkte neue Interesse der Regisseure vereinzelt. Das heurige Jubiläum war kein Signal für eine GrillparzerRenaissance auf den deutschen Bühnen. Selbst in Wien gab es neben der Libussa im Volkstheater als einzige Burgtheater-Neuinszenierung den König Ottokar. Die Medea, die man dort zu sehen bekam, stammt von Hans Henny Jahnn.

Ohne Zweifel besteht ein Mißverhältnis zwischen dem vertieften und differenzierteren Grillparzerverständnis, das die Forschung der jüngsten Dezennien erbracht hat und Grillparzers heutiger Präsenz im Theater und im literarischen Leben. Wer sich in Grillparzers Dramen eingelesen hat, weiß, wie sehr ihre subtile Komposition zu immer erneuter Beschäftigung lockt. Darum gehören Grillparzer-Seminare zu den anregendsten und dankbarsten Lehrveranstaltungen. Es besteht eine Diskrepanz zwischen solch akademischer Faszination und der mangelnden Motivation der Theaterpraxis. Anläßlich des Londoner GrillparzerSymposions 1986 sagte Robert Pichl, die 'Tendenzen der neueren Grillparzerforschung' überblickend:

[Es ist] grundsätzlich zu bedauem, daß bis heute kaum emsthaft versucht wurde, die

1. In: Die Bühne, Wien, Oktober 1990. S. 94. 
Ergebnisse der Grillparzerforschung für aktuelle Bühneninszenierungen anzuwenden, wie dies bei Schiller, Kleist und Büchner längst geschehen ist. Möglicherweise ist die für Österreich beschämend geringe Zahl von Aufführungen bzw. Neuinszenierungen seines 'größten Dichters und typischsten Repräsentanten' auch darauf zurückzuführen. ${ }^{2}$

Und H. H. Hahnl in seiner bereits zitierten Libussa-Besprechung: "Grillparzers 'Libussa' ist ein Lieblingsstück der Interpreten. Sie haben die Regisseure an scharfsinnigen Interpretationen [...] bei weitem übertroffen." Auch bei den Grillparzer-Tagen auf Burg Forchtenstein habe "die Grillparzer-Pflege [...] weniger auf der Burgbühne als im Rittersaal bei den Symposien" stattgefunden. ${ }^{3}$ In mancher Hinsicht sind wir heute Grillparzer nähergekommen. In anderer ist er uns fremd geworden. Noch immer gibt es für uns Entdeckungen zu machen, richtet er Fragen an uns und stellt uns Aufgaben. Längst sind wir mit ihm nicht fertig.

Grillparzer hat sich selbst immer wieder im Gegensatz zu seiner Zeit gesehen: als Unzeitgemäßen in seinem Denken und Schaffen, unverstanden in seinem Wollen, als Dichter von der Staatsgewalt unterdrückt und beargwöhnt, von seinen Zeitgenossen entmutigt. Gegen Ende seines Lebens schrieb er den Vierzeiler:

Will unsre Zeit mich bestreiten,

Ich laß es ruhig geschehen:

Ich komme aus anderen Zeiten

Und hoffe in andre zu gehen.

Auf die oft zitierten Verse bezieht sich der Titel meines Vortrags. Sie sind mein Thema.

Die Eintragung des einundsiebzigjährigen Grillparzer ins Stammbuch der Gräfin Enzenberg vom Februar 1860 setzt der Opposition der gemeinsamen 'Zeit' in resignativem Stolz das Bewußtsein seiner Teilhabe an 'anderen', besseren Zeiten entgegen: den vergangenen, die ihn geprägt, den zukünftigen, von denen er sich Verständnis und Anerkennung für sein Werk erhofft. Zu fragen ist nach Art und Gründen von Grillparzers 'Unzeitgemäßheit' im Koordinatenfeld seiner Zeitbedingtheit und Zeitgenossenschaft, sowie nach der Befähigung seines Werks, die Zeit seines Autors zu überdauern.

Es ist ein sehr langes Leben gewesen, in dessen Verlauf sich die Welt gewaltig geändert hat. Grillparzers erstes Jahrzehnt war noch das letzte des 18 .

2. Robert Pichl, "Tendenzen der neueren Grillparzerforschung." In: Grillparzer und die europäische Tradition. Londoner Symposion 1986. Hrsg. von Robert Pichl, Alexander Stillmark, Fred Wagner und W. E. Yates, Wien 1987. S. 153.

3. In: Die Bühne, Wien, Oktober 1990. S. 94. 
Jahrhunderts, dessen Geist sein Denken verhaftet blieb. Hineingeboren in die Französische Revolution und ihre Kriege, mit Bonapartes Aufstieg und dem Ende des Heiligen Römischen Reichs Deutscher Nation und dem österreichischen Kaisertum als den Geschichtsdaten seiner Jugend, starb er in die Reichsgründung Bismarcks hinein. Der Achtzehnjährige hatte 1809 bei der Besetzung Wiens durch die Franzosen noch Napoleon gesehen, und obwohl er den Feind Österreichs haßte, war er wie magisch von Napoleon angezogen. "Mit dem Haß im Herzen und zu aller Zeit kein Liebhaber von militärischen [!] Schaugepränge", so lesen wir in der Selbstbiographie, "versäumte ich doch keine seiner Musterungen in Schönbrunn. [...] Er bezauberte mich wie die Schlange den Vogel."4 (Sein kranker Vater aber, nachdem er bettlägerig die Bedingungen des Preßburger Friedens gelesen hatte, in denen ein Drittel der Monarchie abgetreten wurde, "kehrte sich gegen die Wand. Von da an hat er kaum mehr ein Wort gesprochen." ${ }^{5}$

Grillparzer wurde ein scharfsichtiger und sachkundiger Beobachter der wechselvollen geschichtlichen Szene mit ihren Erschütterungen und Umwälzungen. Der Reisende in der Postkutsche wurde zum Zeitzeugen der Industriellen Revolution. Der März 1848 markierte auch ihm den geschichtlichen Schnitt des Jahrhunderts. "Kaiser Franz in seiner Engherzigkeit und Gedankensteifheit hatte beschlossen, seinen Staat von allen Neuerungen entfernt zu halten", schrieb Grillparzer in seinen Erinnerungen aus dem Revolutionsjahre 1848. "Kurzsichtig, aber in der Nähe scharf sehend, führte er zu diesem Ende einen Polizeidruck ein, der in der neueren Geschichte kaum ein Beispiel hat."6

Auf grobes Mißverständnis waren Grillparzers österreichische Geschichtsdramen gestoßen: König Ottokars Glück und Ende von der Zensur zurückgehalten, dann durch die Laune des Zufalls doch gespielt und aus Furcht vor Protesten plötzlich wieder abgesetzt; bei Ein treuer Diener seines Herrn, mit seinem unpathetischen, skurrilen Helden und seiner komplexen Problematik witterte der Kaiser Franz Subversion und erbot sich, das Stück für eine Entschädigungssumme als sein Eigentum zu erwerben. Der Patriotismus des Dichters des 'österreichischen Mythos' fand im realen Österreich alles andere als Ermunterung. Die Lust an diesem Genre, in der Nachfolge Shakespeares geplant, war ihm vergällt.

Der Polizeistaat hat seine Schaffenskraft gelähmt, sein Leben vergiftet. Wie hätte Grillparzer nicht das Ende der Ära Metternichs, die Durchsetzung der Bürgerrechte erstreben und begrüßen sollen? Doch so sehr er auch an dem

4. Franz Grillparzer, Sämtliche Werke. Ausgewählte Briefe, Gespräche, Berichte. Hrsg. von Peter Frank und Karl Pörnbacher. 4 Bände. München 1960-65. (Im folgenden zitiert mit $G W$, dann Band und Seitenzahl). Hier: $G W$ Bd. 4, S. 57.

5. Ebd.

6. Ebd. S. $205 f$. 
"schändliche[n] Geistesdruck in Österreich" litt, so war ihm, wie es eine Tagebuchaufzeichnung sagt, "nicht jedes Mittel recht [...], ihn abzuschütteln."7 Nach anfänglicher Sympathie für die Revolution von 1848, sagte er sich plötzlich radikal von ihr los. 1830, nach der Vertreibung Karls X., hatte er in sein Tagebuch geschrieben:

[...] immer besser, als der Geist erliegt und die edelsten Bedurfnisse des Menschen werden einem scheußlichen Stabilitätssystem zum Opfer gebracht. Uberhaupt gibts wohl kein anderes Mittel, die Zeit zu reinigen, und dem vorherrschenden Egoismus die Wage zu halten, als den Staat, und die Teilnahme aller an seinen Interessen. ${ }^{8}$

Dann aber, aus Angst vor dem Zerfall des österreichischen Vielvölkerstaats, dem Bollwerk gegen drohendes Chaos, hat er sich radikal von der Revolution losgelöst. Diese Überzeugung überwog jede andere Erwägung und hatte für ihn absolute politische Priorität. So kam es zu jenem berüchtigten Gedicht auf den Feldmarschall Radetzky ('In deinem Lager ist Österreich'), das zur Restitution der Ordnung den Einsatz der Armee forderte. Der reformbegehrende kosmopolitische Humanist erhielt das Etikett 'Reaktionär'. Mit der uns zugewachsenen geschichtlichen Erfahrung und angesichts der Auflösungsprozesse im SowjetImperium und in Jugoslawien können wir vielleicht Grillparzers Dilemma besser verstehen und seine Angst.

Jener Singular 'Zeit' des Epigramms, der Zeit, der der greise Grillparzer attestierte, daß sie ihn 'bestritt', subsumiert eine Vielheit disparater und konträrer Strömungen des bereits zu zwei Dritteln vergangenen 19. Jahrhunderts. Früh- und Spätromantik, Biedermeier und Vormärz, bürgerlicher Realismus sind die 'Epochen' der Literaturgeschichte. Er ist ihr Zeitgenosse gewesen und blieb von keiner unberührt, in unterschiedlichem Grade beeinflußt. Denn nicht nur 'bestritten' hat ihn seine Zeit, sondern naturgemäß auch bedingt und bestimmt. Das Erdbeben der Französischen Revolution, die Welt im radikalen Wechsel aller Verhältnisse, Aufstieg und Zusammenbruch maßloser Macht, die bestürzende Ungesichertheit alles Bestehenden, dies war die nachhaltige Erfahrung seiner Jugend gewesen. Der politischen Umwälzung war die große europäische Geistesbewegung der Romantik seismographisch verbunden. In dem typologischen Spannungsfeld von Romantik und Realismus, das in europäischer Perspektive die Literatur des 19. Jahrhunderts fundamental strukturiert, hat sich auch Grillparzer bewegt. Der deutschen Romantik hingegen stand der Österreicher in kritischer Distanz und deutlicher Antipathie gegenüber. Er schalt das

\footnotetext{
7. Tagebuch (im folgenden Tgb.) 4025 (1849). Ebd., S. 717.

8. Tgb. 1826 (5.8.1830). Ebd., S. 462.
} 
Verstiegene und Überhitzte und den Mangel an Gestaltungskraft. Den Kult des Irrationalen und Phantastischen lehnte er ab, so wie den des Mittelalters und Primitiven. An der Frühromantik befremdete ihn die Hypertrophie des Subjektiven, das Übergewicht abstrakter Reflexion über konkrete Gestaltung, der Hang zu Entwürfen und Skizzen, Programmen und Postulaten. Er hingegen wollte und wertete das gelungene Werk. Grundsätzlich ablehnend blieb er, der zeitlebens auf dem Boden Kants stand, der nachkantischen idealistischen Philosophie gegenüber, der geistigen Matrix der frühen deutschen Romantik. Was ihn an ihrer späteren regressiven Phase vor allem anwiderte, war das Forcierte und Affektierte ihres Nationalismus und ihrer Religiosität, das Unechte. Im Kontrast dazu erschien ihm sogar die seinen Prinzipien konträre Tendenzliteratur des 'Jungen Deutschland' als lobenswert: "Die faselnd-mittelalterliche, selbsttäuschendreligiose, gestaltlos-nebelnde [...] unfähige Periode hat lange genug gedauert", schrieb er 1836, und die Unsinnigkeit des Verbots der Schriften des 'Jungen Deutschland' betonend, lobte er, was "gegenwärtig in Deutschland sehr fehlt", die, "wenn auch täppische, Geradheit" dieser "junge[n] Schule." "Sie macht sich keine Illusionen." 9 Heine, den er in Paris getroffen hatte und sympathisch fand, attestierte er bei aller Kritik: "Heine ist für jeden Fall eine sehr begabte Natur"10, und Heine schrieb 1833, er rechne Grillparzer zu seinen Freunden, "denn ich hege die beste Meinung von Ihnen. Ich habe Sie von jeher sehr gut verstehen und darum verehren können."11 Eine Verwandtschaft mit Heine spürt man in Grillparzers großer satirischer Begabung, die wir in Nebenwerken kennenlernen, etwa dem köstlichen Schreiben Gottes an den Bürgermeister Hirzel in Zürch. ${ }^{12}$ Dann natürlich das umfangreiche Corpus seiner Epigramme, längst nicht genügend gekannt und gewürdigt. Grillparzers gemeisterte Kurzform durch all die Jahre, Produkte der Welt- und Selbstbeobachtung, an Tiefblick und pointierter Verdichtung ihresgleichen suchend. Grillparzers Epigramme waren Früchte einsamen Meditierens, die seiner Einsamkeit gemäße literarische Form, ihrem Charakter nach monologisch.

Grillparzers zentrale Schaffenzeit (vorausging ein Jahrzehnt vielfältiger, interessanter Juvenilia abseits der Öffentlichkeit) gehört der Epoche der 'Restauration' an. Diesem literarischen Epochenbegriff, oder dem gleichsinnigen des 'Biedermeier' wird Grillparzer zugeordnet. Grillparzer als Autor des 'Biedermeier'. Die Etikettierung hat einst heftige Proteste provoziert. ${ }^{13}$ Heute ist
9. Tgb. 2856 (1836). $G W$ Bd. 3, S. 802.
10. Tgb. 4234 (1855). Ebd., S 801.
11. Brief vom 13.11.1833. GW Bd. 4, S. 795.
12. GW Bd. 3, S. 90 f.
13. Reinhold Backmann, "Grillparzer und die heutige Biedermeier-Psychose". In: Jahrbuch der Grillparzer-Gesellschaft 33 (1935). S. 1-32. 
die 'Biedermeierzeit' (Im Spannungsfeld zwischen Restauration und Revolution, so der Titel von Friedrich Sengles dreibändiger Epochendarstellung) umfassender und differenzierter gesehen, das 'Abgründige' hinter der Idylle aufgedeckt. Demnach kann Grillparzer ohne jede abschätzige Konnotation als zentrale Figur des Biedermeier gewertet werden. Franz Grillparzer oder das abgründige Biedermeier überschrieb Heinz Politzer seine einfühlsame, reizvolle Monographie (1972 erschienen, zum heurigen Jubiläum wieder aufgelegt). Schon vorher hatte Ulrich Fülleborn, die Restaurationszeit unter dem Aspekt des Frührealismus begreifend und damit der dominanten literarischen Tendenz des 19. Jahrhunderts subsumierend, Grillparzer als umfassenden Repräsentanten der "ersten Phase des literarischen Realismus" dargestellt und gemeinsame Epochenmerkmale mit seinen Generationsgenossen Stifter, Mörike und der Droste herausgearbeitet. ${ }^{14}$ Überraschend und überzeugend erweist sich auch Grillparzers innere Nähe zu dem um zwei Jahrzehnte jüngeren Büchner, in Bezug auf den 'negativen Helden' und die spontane Unmittelbarkeit, des 'erweislosen' szenischen Geschehens, bei Grillparzer eine der beiden Konstituenten seiner Dramenstruktur, die andere ist die der ideellen und kausalen Durchformung. Weil bei Grillparzer "Verstand und Vernunft ihre eigene Wirklichkeit haben", werde von ihm "die Epochengestalt des deutschen Frührealismus [...] universaler repräsentiert" als von Büchner, der aber gerade wegen dieses Mankos "zu Recht als Vorläufer und großes Vorbild des 'modernen Theaters' gilt. ${ }^{15}$ Der Bezugsrahmen der literarhistorischen Epochen rückt das individuelle Werk in synchrone Zusammenhänge, durch die sich neue Aspekte eröffnen. Der "Geschichtsschreiber der Dichtung", so Fülleborn einleitend, "verbindet, was im Leben nicht verbunden war, zieht Linien aus, wo ihm die zeitliche Distanz Bezüge wahrzunehmen gestattet." ${ }^{16} \mathrm{Im}$ geschichtlichen Rückblick auf Grillparzer fällt neues Licht auf das Verbindende des gemeinsamen Zeithintergrunds. So bei dem Antipoden Hebbel ("der Mann weiß alles. Er weiß zum Beispiel, wie unser Herrgott entstanden ist, ich aber weiß das nicht", bemerkte Grillparzer über ihn), ${ }^{17}$ oder bei dem anderen, ihm wesens- und werkfremden, deutschen Dramenschöpfer des Jahrgangs 1813, Richard Wagner. Friedrich Hebbel, den Holsteiner, seit 1845 in Wien und gefeierter Burgtheaterautor, kannte Grillparzer gut aus lokaler Nachbarschaft und kollegialem Interesse; auch über Wagner wußte er aus musikalischer Antipathie bestens Bescheid (hatte ihn sogar persönlich getroffen). Von Büchner, dem dritten 1813er,

14. Ulrich Füllebom, Das dramatische Geschehen im Werk Franz Grillparzers. Ein Beitrag zur Epochenbestimmung der deutschen Dichtung im 19. Jahrhundert. München 1966.

15. Ebd., S. 319.

16. Ebd., S. 8.

17. Hier zitiert nach Josef Nadler, Franz Grillparzer. Vaduz 1948. S. 815. 
wußte er wohl nichts. Der hergestellte Bezug ist rein werkimmanent. Der sich aufdrängende kontrastive Vergleich ist der mit Heinrich von Kleist: geboren vierzehn Jahre vor Grillparzer, hat er sieben Jahre vor Grillparzers Bühnendebüt und dem Beginn der Restaurationsepoche seinem Leben ein Ende gemacht. Wie Grillparzer war er ein Solitär.

Wie nötig und ergiebig auch die Perspektive des epochalen Koordinatenfeldes ist, es ist natürlich nicht die einzige Sicht eines 'Geschichtsschreibers der Dichtung'. Das Individuelle entzieht sich dem Raster der begrifflichen Einordnung, umsomehr, je eigenartiger das zu Sichtende ist. Das Kriterium der Epochenrepräsentanz ist eine Orientierungshilfe, kein Wertmaßstab. Für den Dichter, der nach seinem Selbstverständnis quer zu seiner Zeit steht, kann (nimmt man ihn ernst) der Hinweis auf seine Konformität nur als relativierende Korrektur gelten. Der Einwand Fülleborns, daß 'Ich komme aus anderen Zeiten / Und hoffe in andre zu gehen' auch jeder andere "der bedeutenden Zeitgenossen Grillparzers zu sagen vermocht" hätte, ${ }^{18}$ mag zutreffen auf eine allgemeine Zeittendenz. Es ist aber gerade das Besondere in Wortlaut und Tonlage der Selbstaussage Grillparzers, das mein Thema ist und meine Sicht bestimmt. Was in den Blick kommt ist das Besondere des Gehalts, ein ganz Persönliches, Unvergleichliches, das jene vier Verse kondensieren, ein Objektivierbares hinter der subjektiven Aussage, etwas Präzises, Präzisierbares und doch etwas, das rätselhaft bleibt. "Ihr kennt Grillparzer gar nicht", schrieb Ferdinand Kürnberger in der Berliner Börsenzeitung (23.1.1872) zu Grillparzers Tod, "von dem ganzen Grillparzer ging nur eine Hälfte über die Erde: die andere Hälfte ist niemals gesichtet worden."

Scheu sich mitzuteilen, verbarg er sich hinter Masken, auch der Larmoyance. Ein 'Raunzer', ein Hypochonder. Aber, ohne Pose, auf dem Grunde seiner Seele das destruktive Potential, das ihn ängstigte, das elterliche Erbteil. Der steife, gehemmte Vater, unfähig zu jedem Gefühlsausdruck. Die sensitive, hochmusikalische Mutter, für die und seine drei jüngeren Brüder er nach dem Tod des Vaters in inniger Verbundenheit sorgte. Die Mutter eines Nachts erhängt in den Händen zu halten, das war das sehr reale Trauma, über das er sein Leben lang schwieg. Zwei Jahre vorher der Suizid des jüngsten Bruders mit siebzehn Jahren aus Angst, kriminell zu werden ("Da ich immer mehr und mehr in das Stehlen hineingekommen wäre"). ${ }^{19}$ Der Zweitälteste, ein kleiner Kanzlist, der Geld unterschlug und sich verwirrt eines Mordes bezichtigte. Der Dichter, der während seiner Englandreise davon unterrichtet wurde, setzte sich bei den Behörden für den Bruder ein. In einem diesbezüglichen Brief schreibt er abschließend: "[...] werde nur suchen, die Familienkrankheit der Söhne meines Vaters nicht im ganzen Maße auch auf mich übergehen zu lassen." 20

\footnotetext{
18. Ulrich Fülleborn, vgl. Anm. 14, S. 8 .

19. Briefe (1817) GW Bd. 4, S. 739.
} 
Doch bei ihm schlug das Abnorme um in Kreativität. Er litt an Melancholie und Depression als 'Familienkrankheit'. Er beschreibt die Symptome seiner nervlichen Überreiztheit ("Mein Geist ist den Krämpfen ebenso unterworfen als mein Körper. [...] wenn all [...] diese Anspannungen entfernt sind [...], kommt gewöhnlich auch die Poesie." $)^{21}$ und seine krankhafte Berührungsangst. Der Theateraufführung eines seiner Stücke beizuwohnen, bereitete ihm physische Qual. Seelische Entblößung empfand er als so 'unschicklich' wie körperliche. Und war doch der theaterbewußteste deutsche Dramendichter, der stets in Gedanken an Bühne und Publikum schrieb. Er war ein 'Zerrissener', von der Dissonanz entgegengesetzter Veranlagungen gequält - 'Verstandeskälte' und 'glühende Phantasie' nebeneinander. ${ }^{22}$ Die Niederschrift seiner: "inneren Zustände" würde, so meint er, den Eindruck der "Krankengeschichte eines Wahnsinnigen" machen. "Das Unzusammenhängende, Widersprechende, Launenhafte, Stoßweise darin übersteigt alle Vorstellung. Heute Eis, morgen in Flammen. Jetzt geistig und physisch unmächtig, gleich darauf überfließend, unbegrenzt." (1827). ${ }^{23} \mathrm{DiC}$ Pedanterie seiner Beamtenexistenz mit ihren Demütigungen, in die seine drei Auslandsreisen etwas Abwechslung brachten, war doch benötiger Halt. Vor der Bindung der Ehe scheute der bei seiner Gehemmtheit und Spröde erotisch sehr impressionable und attraktive Mann zurück. Die beklagte Haltlosigkeit und Zerrissenheit seiner Natur rief er mit Willensdisziplin zur Ordnung. Bei aller Inkonsequenz im einzelnen beansprucht er für sich, er sei "eisern konsequent im ganzen". ${ }^{24}$

In seinen Tagebüchern unterzog sein scharfer, klarer Verstand das Dunkle und Dämmrige der psychischen Motive einer gnadenlosen Analyse. Der Angst vor den Gefahren, die den Staatskörper bedrohten, korrespondierte die Angst vor der Bedrohung aus dem eigenen Innern. Aus dieser Motivation hier wie dort weist seine psychologische Hellsicht, wie seine politische, weit über seine Zeit hinaus. Das einzigartige psychologische Gespür des Dramatikers beruhte auf der Selbsterfahrung einer gepeinigten Seele und hatte die selbstquälerische Selbstbeobachtung des Tagebuchschreibers zur Voraussetzung. Doch die Modernität seines psychologischen Realismus bleibt der geistigen Wirklichkeit eines geistigen Kosmos verbunden, die, wenn auch in der Welt nicht realisiert, als

20. Brief an Theodor Georg von Karajan (30.6.1836). Ebd., S. 815.

21. $T g b .1050$ (1822). Ebd., S. 369.

22. So heißt es in der Selbstbiographie: "In mir nämlich leben zwei völlig abgesonderte Wesen. Ein Dichter von der übergreifendsten, ja sich überstürzenden Phantasie und ein Verstandesmensch der kältesten und zähesten Art." Ebd., S. 88.

23. Tgb. 1615 (16.9.1827). Ebd., S. 433.

24. Tgb. 1634 (1828). Ebd., S. 444. 
Wertmaßstab und utopische Perspektive das dramatische Gegengewicht darstellt. Auch hält Grillparzers Drama, das mit noch nie so gesehenen Verkörperungen psychischer Hintergründigkeit über seine Zeit hinausgreift, dennoch an der Versform der 'poetischen Zeiten' fest. Auch wenn sich sein Realismus gegen den Fluß des klassischen Jambus sperrt, gegen die Angst vor den Dämonen im eigenen Innern sucht er die Bannkraft der klassischen Form. Grillparzer reagierte auf die skandalöse Ablehnung von Weh dem der lügt! bei der Burgtheaterpremiere am 6. März 1838 durch seinen Abschied von der Bühne, der unwiderruflich blieb. Diese Zäsur teilt Grillparzers reife Schaffenszeit in zwei Hälften: Einundzwanzig Jahre mit acht Uraufführungen auf der einen Seite, auf der anderen vierunddreißig Jahre mit drei Dramen, die in der Schublade verblieben.

Grillparzers Isolation war tief, aber keineswegs absolut. Seinen Dramen war Anerkennung und Bewunderung zuteilgeworden. Am Ende seines Lebens regnete es Orden und Huldigungen, was er freilich nur noch mit bitterer Ironie quittieren konnte. Dazwischen lagen die 34 Jahre der Abschottung von der Theateröffentlichkeit. Kein in sich verschlossener Eremit, sondern wachen Geists der klarsichtige Beobachter des öffentlichen Geschehens. Kein deutscher Dichter des Jahrhunderts hatte so viel politischen Sachverstand, wie etwa seine brillante Charakteristik Metternichs beweist. ${ }^{25}$ Seine Umgangsformen waren österreichisch urban. Doch sein liebster Umgang waren die großen Dichter der Weltliteratur, die er andächtig und kritisch studierte, die großen Spanier vor allem. "Großes zu denken", war ihm selbst wichtiger als die eigene Produktion. Doch er arbeitete immerfort an seinen großen Altersdramen.

Hier sitz ich unter Faszikeln dicht,

Ihr glaubt, verdrossen und einsam -

Und doch vielleicht - das glaubt ihr nicht:

Mit den ewigen Göttern gemeinsam. ${ }^{26}$

Im Blick auf Ewiges beurteilte er seine Zeit, ein "Dichter der letzten Dinge", als den er sich verstand. In dieser Sicht relativierte sich ihm seine Zeit, zu deren "Grundirrtümern" in den wechselnden Meinungen und Bestrebungen er sich in prinzipiellem Widerspruch fand und von der er sich mehr und mehr löste.

Grillparzers Kritik an seinen Zeitgenossen war grundsätzlich. Sie setzte immer dort an, wo er den Grundirrtum seiner Zeit sah: bei dem falschen Bewußtsein einer irregeleiteten Bildung. Die Maßstäbe seiner eigenen Bildung hatte er von der Aufklärung und Klassik des 18. Jahrhunderts erhalten. Er selbst hatte noch Goethe persönlich kennengelernt, 1826, als er fünfunddreißig Jahre alt den Siebenundsiebzigjährigen in Weimar besuchte, überwältigt von dem "Ideal

25. Vgl. Studien und Aufsätze III. GW Bd. 3, S. 1022-1037.

26.

Epigramme (1855). GW Bd. 1, S. 530. 
meiner Jugend", "der mir die Verkörperung der deutschen Poesie, [...] beinahe zu einer mythischen Person geworden war". ${ }^{27}$ Goethes Humanismus ist ihm wegweisend und richtunggebend geblieben im Verein mit den durch das gemeinsame Ethos verbundenen Geistesverwandten der Aufklärung und Klassik, mit Lessing, Kant, Schiller. Dort war sein Denken verwurzelt. Auf diesem Boden stand er, wollte er stehen:

\section{Nur weiter geht das tolle Treiben, \\ Von vorwärts! vorwärts! erschallt das Land; \\ Ich möchte, wärs möglich, stehen bleiben, \\ Wo Schiller und Goethe stand. ${ }^{28}$}

Er wußte, das dies nicht möglich war. Der irreale Konjunktiv sagt es unmißverständlich. Grillparzer wollte keine Restitution von Vergangenem. Was seinen Ohren mißklang, war die sich breitmachende kritiklose Fortschrittseuphorie. Fortschritt als Triumphzug der Technik, mit Kapitalismus und Imperialismus im Bund. Ein Fortschritt allein der instrumentalen Vernunft. Die Entfaltung einer Eigendynamik ohne Mäßigung, ohne Ziel und Sinn. Grillparzer aber stellte die Sinnfrage, im Blick auf den mündigen Menschen. Und gemessen an dem Menschenbild Schillers und Goethes erschien der Fortschritt als Rückschritt. Es war die Überantwortung an die selbstgeschaffenen Zwänge von Markt und Macht, die Absage an den Geist als realitätsformende Kraft. 'Stehen zu bleiben' bei Schiller und Goethe, impliziert, im Sinne wahrer Bewahrung klassischer Tradition, die immer neue Aktivierung der als gültig erkannten Normen. Demnach wäre echter Fortschritt eine Hinaufbewegung auf die Idee des Menschen und der Menschheit zu, im Sinne der Utopien von Rudolf II. und Libussa. Aber der Weltzustand in Grillparzers Zeiterfahrung war gekennzeichnet durch den Verlust menschlichen Maßes. Die Signatur des Zeitalters waren der sich als absolut setzende Individualismus schrankenloser Macht- und Raffgier und die egozentrische Verabsolutierung der Nation zu regressivem, weltblindem Nationalismus. Dazu die geistige Dominanz des Historismus mit der Schwächung der authentischen Erfahrung in der Hypertrophie des Angelernten und Anempfundenen und der Relativierung aller Werte als Konsequenz. Dagegen opponiert Grillparzer mit seinem ganzen Wesen und Werk. Seine Kritik richtete sich nicht gegen historisches Wissen, sondern gegen eine Beschäftigung mit der Vergangenheit ohne Bezug zur eigenen Gegenwart. Historie als Lebensersatz. Es geht um die zentrale Wertfrage in Bezug auf die grundsätzlichen Probleme der Bildung. Grillparzer kam immer wieder darauf zurück. In falscher Bildung sieht er die

27. Selbstbiographie. GW Bd. 4, S. 144 u. 146.

28. Epigramme. (Januar/Februar 1846); "jambische Umformung" des Epigramms 'Endlos ist das tolle Treiben' von 1844. Vgl. GW Bd. 1, S. 1257 u. 461. 
Quelle allen Übels.

Mit aller Entschiedenheit wehrte sich Grillparzer gegen die Hypertrophie und Hybris des Begrifflichen, das ohne den Prüfstein der Empirie und des Gefühls das Augenmaß für die humane Wirklichkeit verlor, die Realität eintauschend für ein Hirngespinst. Seine Antipathie richtete sich natürlich gegen Hegel, mehr noch gegen dessen simplizierende Schüler, links und rechts, deren Systemdenken dominierte. Hier sieht er die Wurzel jenes Verfalls der "neueren deutschen Bildung", den er beklagt. Denn diese Art Bildung habe die natürliche Empfindung der Deutschen untergraben. ('Empfindung' als zwischen Vernunft und Gefühl vermittelnde Instanz ist ein zentraler Begriff Grillparzers). In einem maßlosen Dünkel habe man sich daran gewöhnt, angesammeltes und übertragbares Wissen für ein persönliches Verdienst zu halten, das Wissen mit dem Können zu verwechseln. Auch habe man sich entwöhnt, selber zu denken und zu schauen und behelfe sich aus zweiter Hand mit Surrogaten. Grillparzer notiert in sein Tagebuch:

Durchbildung ist ein sehr gutes neues Wort und zeigt an, daß ein Mensch so von Bildung durchdrungen ist, daß nach Austreibung alles Natürlichen, er sich als ein ausgespritztes anatomisches Präparat darstellt. ${ }^{29}$

Das der Kontrolle der eigenen Empfindung enthobene Denken wird zum Werkzeug der Ideologien. Der menschliche Geist, aus dem humanen Bezug gelöst, hinterläßt eine lichtlose Seele, offen für jede Verführung und den eigenen Dämonien preisgegeben. Den alten Grillparzer peinigte die Angst vor der Rebarbarisierung: "Aus eigener Brust ringt los sich der Barbar", heißt es im Bruderzwist. Und das in seiner prophetischen Klarsicht erschütternde Notat aus dem Jahr 1848, das in epigrammatischer Pointierung den eingeschlagenen Irrweg blitzartig erhellt: "Der Weg der neueren Bildung geht./ Von Humanität / Durch Nationalität / Zur Bestialität. ${ }^{\text {"30 }}$ Grillparzer stand fest auf dem Boden der Aufklärung. Wo in den Massen das 'sapere aude' des mündigen Individuums nicht galt und der Nationalismus des Jahrhunderts sich von der Idee der Humanität entfernte, erschien ihm der vielberufene Fortschritt fragwürdig.

Als verhängnisvoll beurteilte Grillparzer die Konsequenz der 'neueren Bildung' für die Literatur:

Das ist das Unglück der Deutschen als Schriftsteller daß keiner sich mit seiner eigenen Natur hervorwagt. Jeder glaubt, er müsse mehr sein als er selbst. ${ }^{31}$

29. Tgb. 4153 (1857). GW Bd. 3, S. 699.

30. $G W$ Bd. 1, S. 500 .

31. Tgb. 3192 (1836/37). GW Bd. 3, S. 699. 
In Österreich stünde es in dieser Hinsicht besser. Dort gelte noch "wahres Gefühl" und der "gesunde Menschenverstand." ${ }^{32}$ Eigenschaften, die er dem Wiener Theaterpublikum zuerkannte. Sie hatten ihr eigenes Urteil. Kein anderer deutscher Dramatiker von Rang achtete das Publikum so hoch. Die Zuschauer seien zwar nicht die gesetzeskundigen "Richter", doch die mit "natürlicher Empfindung" begabte "Jury." ${ }^{33}$ Jedenfalls sei das so in seiner Jugend gewesen. Später sei auch hier Verderbnis eingetreten. Grillparzer hatte die konkrete Aufführung stets im Blick. Er hielt nichts von Lesedramen. Die Ablehnung seines 'Lustspiels' mußte ihn daher besonders hart treffen. Sein dauernder Verzicht auf die Bühne als Folge war ein sehr schmerzlicher Schnitt.

So unverstanden er sich zunehmend empfand, er war ein eminent bodenständiger Dichter. So sehr Grillparzer an den österreichischen Verhältnissen litt, er hat nie ernsthaft daran gedacht, von Österreich fortzugehen: "Hier Landes scheint kein Platz für mich zu sein, und doch wollte ich lieber alles tun und leiden, als es verlassen." ${ }^{34}$ Diese "Fronveste der Seelen" ("Ich hätte dieses Land, halb ein Kapua und halb eine Fronveste der Seelen, zeitig verlassen müssen, wenn ich ein Dichter hätte bleiben wollen.") ${ }^{35}$, über die er bitter klagte, war zugleich seine "Heimat", die er, wie er bekennt, "bis zum Kindischen liebe", ${ }^{36}$ und war der Boden, aus dem sein Werk erwuchs. Der berühmte Zweizeiler hat seine Richtigkeit:

Hast du vom Kahlenberg das Land dir rings besehn,

So wirst du was ich bin und was ich schrieb verstehn.

Dieser Schlüssel zum Verständnis Grillparzers ist ganz wörtlich zu nehmen: vom Kahlenberg, dem waldigen Wachtberg mit Rebenhängen am nordwestlichen Eingang Wiens am Donauufer (wo anno 1683 bei der Türkenbelagerung das Entsatzheer sich formierte) geht der Blick im Westen über das nahe Donautal und die Kuppen des Wienerwald, in denen der Gebirgszug der Alpen sanft ausläuft, während am östlichen Horizont die weite Ebene anhebt und der völkerverbindende Strom meerwärts fließt. So schien Wien, die Hauptstadt des Vielvölkerstaates, zu ruhen zwischen West und Ost, beiden benachbart, beiden verpflichtet, zu versöhnen und zu verschmelzen bestimmt. Österreich, Wien, als Grunderlebnis der Landschaft als Anschauungsunterricht präsenter Geschichte des Heranwachsenden,
32. Vgl. ebd., S. 809ff.
33. Vgl. ebd., S. 734.
34. $T g b .1132 . G W$ Bd. 4, S. 378.
35. Tgb. 1826 (5.8.1830). Ebd., S. 462.

36. Erinnerungen aus dem Revolutionsjahre 1848. Ebd., S. 220. 
ist wesentlich zum Verständnis von Grillparzers Wesen und Werk.

Der österreichische Faktor bei Grillparzer, von Fülleborn heuristisch ausgespart, wurde von anderen Wissenschaftlern herausgearbeitet, so von Robert Mühlher, der Grillparzer in Abhebung vom individualistischen deutschen Idealismus einer katholisch-österreichischen Denktradition zuordnet. ${ }^{37}$ Die Tradition, die bei Claudio Magris zu kurz kommt, der in seinem originellen und anregenden Buch Grillparzer unter den Schöpfern des 'habsburgischen Mythos in der österreichischen Literatur' die zentrale Position zuweist. ${ }^{38}$ In seiner Arbeit über das Wiener Theater im 19. Jahrhundert hat Roger Bauer die Kontinuität eines österreichischen Weltbildes eindrucksvoll aufgezeigt, welches sich, weltbejahend, einer umfassenden Seinsordnung verhaftet, vom Barock über den Josephinismus bis in den Realismus des 19. Jahrhunderts, in allem Wandel erhält. ${ }^{39}$

Goethe und Schiller waren Grillparzers überwältigende Bildungserlebnisse. Die Weimarer Klassik bedeutete für den werdenden österreichischen Dramatiker den Höhepunkt der deutschen Literatur und mit dem hohen Anspruch ihres künstlerischen Niveaus ein Vorbild. Grillparzers Poetik des Dramas blieb den klassischen Normen verpflichtet. Dennoch sah er in der klassischen Leistung Desiderate, die ihm seine Aufgabe stellten: "Das Leben und die Form so zu vereinigen, daß beiden ihr volles Recht geschieht." ${ }^{40}$ Dahin zielt Grillparzers Dramaturgie. Sie soll ergänzen, was den Dramen Schillers und Goethes fehlt.

Was er an der dramatischen Weltliteratur am höchsten wertet und selbst erstrebte, waren die Kraft sinnlicher Vergegenwärtigung, psychologisches Gespür und Subtilität der Komposition. Von daher erschien die Dominanz der Sprache in den klassischen Dramen Schillers und Goethes als einseitig. Er vermißte das Gestische, Mimische. Demgegenüber setzte Grillparzer seine Maxime: "Wort und Gebärde." In ihrem Verbund wurden sie die tragenden Elemente seiner Komposition, wobei der Gebärde entscheidende und neue Bedeutung zukommt.

Bei jenem Besuch des jungen Grillparzer in Weimar hatte Goethe die Sappho gelobt, weil, wie Grillparzer in seiner Selbstbiographie ironisch vermerkt, er "so ziemlich mit [Goethes] Kalbe gepflügt" habe. ${ }^{41}$ In Wahrheit hat er schon damals seinen Acker anders bestellt. Seine dramatische Kunst hatte noch andere Quellen

37. Robert Mülher, "Grillparzer und der deutsche Idealismus. Ein Beitrag zum Säkularisationsproblem." In: Wissenschaft und Weltbild 1 (1948). S. 62-75.

38. Claudio Magris, Der habsburgische Mythos in der österreichischen Literatur. Salzburg 1966.

39. Roger Bauer, La Réalité, Royaume de Dieu. Études sur l'originalité du théâtre viennois dans la première moitié du XIXe siècle. München 1965.

40. Tgb. 1605 (1827). GW Bd. 4, S. 430.

41. Selbstbiographie. GW Bd. 4, S. $147 f$. 
und Vorbilder. In seiner Selbstbiographie steht dieser Schlüsselsatz: "Meinen Werken merkt man an, daß ich mich in meiner Jugend an den Geister- und Feenmärchen der Leopoldstadt ergetzt habe." Die Eindrücke des Wiener Volkstheaters sanken tief und blieben der Nährboden seiner Phantasie. Ein "veredeltes Volkstheater" hat Max Kommerell die Klassik Grillparzers genannt, und: "Wie fern von Weimar ist mit alledem Wien." ${ }^{42}$ Den Normen der Weimarer Klassik verpflichtet, hat Grillparzer in lokalem Theaterbezug und im weltliterarischen Rückgriff einen höchst persönlichen Dramenstil geschaffen, der zum Teil frappierend modern anmutet. Sein Theatersinn fand in Wien reichlich Nahrung. Die heimische lebendige Barocktradition der Wiener Volksbühne war prägend. Aus den traditionellen Theatereffekten und -requisiten der Leopoldstädter "Geister und Feenmärchen" schuf sich Grillparzer ein differenziertes Instrumentarium zur Darstellung unterschwelligen Bewußtseins und volatiler seelischer Vorgänge. So wurde er der Dramatiker der Genese von Leidenschaften, und ihres Vergehens: des Gefühls, das sprachlos im Vorhof des Denkens keimt und nur in der Gebärde zum Ausdruck gelangt, und dann des Verstummens, das in die Gebärde mündet. Die Gebärde, die auf das Wort unbewußt vorausdeutet, die es bestätigend oder widersprechend begleitet und es ablöst in ihrer stummen Beredtheit. Die Relativierung der Sprache: ein Sprechen, das mehr verrät als es aussagt, das Versprechen, der unterbrochene Satz, die Suggestion des Verschwiegenen. Die Signale des Schaubaren: physische Kontrastierung der Charaktere durch Körpermerkmale, Gestik und Kleidung, Kostümwechsel und Änderung des gestischen Verhaltens signalisieren seelische Befindlichkeit und Sinneswandel. Stufen des Erlebens finden so Ausdruck, die sich dem Wort noch entziehen, wie Medeas verändertes Verhalten zu Peritta, Heros zu Janthe; und solche, an denen das Wort versagt, wie - das großartigste Beispiel - die stumme Szene König Alfons nach der Konfrontation mit Rahels Leiche.

Die detailliert konzipierten Bühnenbilder, Zonen des Tabus und der Fremdheit suggerierend, sollen in der Anschauung zur Geltung kommen vor allen Worten. Konkrete Gegenstände (Kleid, Mantel, Amulett, Lampe) haben sinnfällige dramatische Funktion und gewinnen symbolische Bedeutung, die sich im kompositorischen Zusammenhang ganz erschließt. Kleiderwechsel (barocker Herkunft) als Indikator seelischer Veränderung. Wenn etwa Jason Medea den Zauberschleier abreißt und sie damit von allen dunklen Gewalten lösen will, und wir sie später in griechischer Tracht sehen, und sie endlich das Griechengewand zerreißt, aus Verzweiflung, je eine Griechin zu werden. Generell die Symbolik der konkreten Gegenstände und Bühnenvorgänge. Medea, ihr Zaubergerät vergrabend, weil sie die Vergangenheit vergessen möchte, die sich nicht vergessen und

42. Max Kommerell, Grillparzer. Ein Dichter der Treue. (1936). Jetzt auch in: Franz Grillparzer. Suhrkamp Taschenbuch Materialien. Hrsg. von Helmut Bachmaier. Frankfurt/M. 1991. 
begraben läßt, und wieder heraufbrechen wird mit schicksalhafter Macht. Oder wie sich in einer Geste ein Charakter blitzartig enthüllt, König Ottokar etwa in seiner Hybris, wenn er den Bürgermeister von Prag auffordert, ihm die Beinschiene abzunehmen. Beispiele kommen jedem sofort in den Sinn. Nur das eine, großartige sei genannt: Rudolf II. Eingang im Bruderzwist. Der umrätselte, rätselhafte Kaiser auf dem Hradschin, der menschenscheue Menschenkenner, in seiner Alchimistenküche vergraben und in die Sterne schauend, während sich auf seinem Schreibtisch die unerledigten Staatspapiere häufen. Langsam, auf seinen Krückstock gestützt, tritt er in den Audienzsaal, scheinbar niemanden beachtend, bis er zwei Maler sieht, die ihre Bilder zum Kauf anbieten. Er spricht kein Wort, bezeichnet nur am eigenen linken Arm eine Stelle, die ihm verzeichnet erscheint, und schüttelt den Kopf. Das Bild des anderen gefällt ihm: er hebt drei Finger und bedeutet damit dem Kanzler den Kaufpreis. Der wendet besorgt ein, als habe er nicht genau gesehen: 'Zweitausend?'. Da sagt der Kaiser mit starker und heftiger Stimme: 'Drei'. Es ist sein erstes Wort. Sein Schweigen fällt seinen Worten voraus wie ein langer Schatten. Sie sind ganz aus dem Schweigen herausmodelliert. Sein siebenmaliges 'allein' im ersten Akt als sehnlicher Wunsch ist beredter als jede Rhetorik. Oder Klang und Kadenz der einzelnen spanischen Wörter, die er beim Anblick von Lope de Vegas Drama Ring des Vergessens beglückt hervorstößt: 'Divino autor', 'Fenix de España', 'Sortija del olvido'. Er hat seines Autors Scheu vor der Sprache. Dann aber weicht seine verdrossene und schwermütige Wortkargheit rhetorischem Pathos. Es sind jene 'Prunkreden', die Herbert Seidler als für Grillparzer stilkonstitutiv erkannt und interpretiert hat. ${ }^{43}$ Es ist ein Pathos, herausgehoben aus dem Bereich des individuellen Lebens. Nicht subjektiver Ausdruck der individuellen Person, sondern Stimme der allgültigen Ordnung des Seienden durch ihren berufenen Sprecher. Nicht Rudolf, sondern der Kaiser. Mit solcher Sprechhaltung barocker Repräsentanz kontrastiert die Modernität von Grillparzers hintergründigem psychologischen Realismus - in der subtilen Expressivität seiner Brechungen und Facettierungen - als die andere Komponente dieses singulären Spannungsgefüges.

Sein poetisches Ideal war die Schaffensweise jener Dichter, die sich der ungeteilten Kraft der Anschauung verdankte, als "die Poesie" von ursprünglichem, durchaus bildlichem Charakter ihre "Berechtigung in der Empfindung und nicht im Gedanken" suchte. Gemeint ist keinesfalls primitive Dichtung, vielmehr die Produkte "jene[r] Dichter [...] die mit Talent und Geist begabt, als die Spitze einer an sich poetischen Zeit jene Einheit abspiegelten, mit der das Leben sie umgab [...]." ${ }^{44}$ Grillparzer nennt "die Griechen, die Spạnier, Ariost und Shakespeare" und

43. Herbert Seidler, "Prunkreden in Grillparzers Dramen." In: Ders., Studien zu Grillparzer und Stifter. Wien 1970. S. 85-117.

44. Tgb. 4025 (1849). $G W$ Bd. 4, S. $716 \mathrm{f}$. 
nennt sie "die Freunde meiner Einsamkeit":

[...] ihre Darstellungsweise mit der Auffassung der neuem Zeit in Einklang zu bringen, mein halb unbewußtes Streben. Da ich aber mit meiner Ansicht in den letzten zwanzig Jahren so ziemlich allein stand, so war es mir nicht möglich, die. Anschauung immer lebendig und rein zu erhalten, um so weniger, als ich durch die traurige Lage der Welt und meines Vaterlandes vielfach zerstreut und gestört, die Ausführung nicht mehr so in einem Zuge vollenden konnte, als für ein solches Verfahren unter solchen Umständen durchaus notwendig wäre. ${ }^{45}$

Ohne Unterbrechung und mit verstärkter Intensität studierte er die großen Dramatiker der Weltliteratur, an denen er gelernt hatte, schon in dem Jahrzehnt seiner zahlreichen dramatischen Versuche vor der Ahnfrau, jetzt "die Freunde seiner Einsamkeit." Immer wieder vor allem das umfangreiche Werk des "göttlichen" Lope de Vega. Im Grunde meint dieses weltliterarische Panorama insgesamt jene 'anderen Zeiten', aus denen Grillparzer nach seinem Selbstverständnis kommt. Sie sind mit der deutschen Klassik zu Ende gegangen. Seine besondere Neigung und höchste Wertung aber gehört den "an sich poetischen Zeit[en]", deren Dichter ganz aus der ungeteilten "Anschauung" schufen. Er bemängelt, daß "die Poesie der Deutschen [...] gegen den natürlichen Entwicklungsgang, erst nach der Wissenschaft entstanden ist." ${ }^{46}$ Auch bei den "vortrefflich[en]" neueren Dichtern sei "so viel Beimischung von Prosa, so viel Lehr- und Reflexionsmäßiges." ${ }^{47}$ Sein Streben sei es gewesen, ein "weniger absichtliches, als durch meine Natur gebotenes", "die Poesie dem ursprünglichen [...] der alten Dichter näher zu bringen, [...] ihre Darstellungsweise mit der Auffassung der neuern Zeit in Einklang zu bringen." Dies ist, "wie es scheint, mir nicht gelungen", heißt es resignierend im Tagebuch von $1849 .{ }^{48}$ Dieser Dichter, der in der Poesie die ursprüngliche "Anschauung" über alles schätzte, ein erklärter Feind des "nackten Gedankens", war selbst im hohen Maße zur Reflexion befähigt. Ihr ist entscheidend geschuldet, wenn ihm dennoch in seinem Werk das Intendierte gelingen konnte und gelang.

Widersprüchlich ist Grillparzers Verhältnis zu den Zeiten, aus denen er kommt. Widersprüchlich das Verhältnis zu seinem Denken und Dichten der auf ihn folgenden Zeiten. Es sind kaum jene, in die er zu gehen gehofft hatte. Die von ihm diagnostizierte Krise des Geistes und des Menschen ist potenziert. Seine Kassandra-Angst haben die Katastrophen eingeholt. Seine Prophetie der Rebar-
45. Ebd., S. 717.
46. Tgb. 3359 (1838). GW Bd. 3, S. 289.
47. Tgb. 4025 (1849). GW Bd. 4, S. 717.
48. $T g b .4025$ (1849). GW Bd. 4, S. $716 \mathrm{f}$. 
barisierung hat sich erschreckend bewahrheitet. Bleiben wir bei der Literatur und bedenken wir das Antizipatorische in Grillparzers Werk, seine 'Modernität'. Damit ist Unterschiedliches und Gegensätzliches angesprochen, da 'die Moderne' im europaïschen Horizont bereits zu Grillparzers Lebzeiten begonnen hat und im gegenwärtigen literarischen Diskurs von der 'Postmoderne' problematisiert und abgelöst wird. Grillparzer wußte nichts von dem epochalen Neuansatz der Lyrik Baudelaires, noch vom Drama des Naturalismus. Beides hätte er abgelehnt.

Jedoch seine prinzipielle Trennung von 'Poesie' und 'Prosa' hat auffallende Entsprechungen in den Formulierungen Paul Valérys (geb. ein Jahr vor Grillparzers Tod), bei Unvergleichbarkeit der dichterischen Intention und Praxis. Wenn Valéry, im Gefolge Mallarmés die Prosa dem Gang, die Poesie dem Tanz vergleicht, so setzt Grillparzer biedermeierlich aber gleichsinnig die Opposition "Spazierfahrt" - "Reise", der Zweck erster liegt "im Weg", nicht im "Ziel"49 -, oder Weingenuß versus Nahrung, ${ }^{50}$ um den kategorialen Unterschied zu veranschaulichen, auf dem er leidenschaftlich insistiert: "Poesie [...] ist nicht die Prosa mit einer Steigerung, sondern das Gegenteil der Prosa." Poesie sei "etwas Göttliches". ${ }^{51}$ Er will sie nicht "zum Gewerbe" machen. ${ }^{52}$ Und in Abhebung von der Poesie und Prosa mischenden "Verstandes- und Meinungspoesie" seiner Zeit schreibt er resümierend und resignierend:

Ich merkte wohl, daß ich als der letzte Dichter in eine prosaische Zeit hineingekommen sei. ${ }^{53}$

Der Begriff der Poesie meint hier immer Gefüge aus Versen. Das Medium der Prosa für sich impliziert Zweitrangigkeit. Grillparzer definiert den Roman als "das Hinaufstreben der Prosa zur Poesie", die Novelle als "Herabneigen der Poesie zur Prosa. ${ }^{154}$ Diese Hierarchie der Gattungen ist klassizistische Poetik und erscheint im Jahrhundert der großen Romane obsolet. Er selbst hat in dankenswerter Inkonsequenz mit Der arme Spielmann eine große, unsterbliche Prosadichtung geschaffen, das großartige Gegenbeispiel zu seiner theoretischen Abwertung der Prosa. Doch sein obstinates Festhalten am Vers indiziert in seiner apologetischen Heftigkeit die Übermacht der Zeitströmung, gegen die er anzukämpfen strebte: als "der letzte Dichter in eine[r] prosaische[n] Zeit." Als das "Zeitalter der Prosa" hat

\footnotetext{
49. Tgb. 3412 (1838). GW Bd. 3, S. 290.

50. Vgl. Tgb. 1176 (1822), GW Bd. 3, S. 289 und Tgb. 3493 (1839), GW Bd. 3, S. 290 .

51. Tgb. 3492 (1839). Ebd., S. 290.

52. Vgl. Tgb. 1633 (1828). GW Bd. 4, S. 444.

53. Selbstbiographie. GW Bd. 4, S. 80.

54. Tgb. 3281 (1837). $G W$ Bd. 3, S. 291.
} 
Hegel sein Zeitalter einer poetisch ergiebigen Vergangenheit entgegengesetzt (Hegel konstatiert das Fehlen des "ursprünglich poetische[n] Weltzustand[s]", das mit der Innerlichkeit des Künstlers übereinging. "Der Roman im modernen Sinne setzt eine bereits zur Prosa geordnete Wirklichkeit voraus".), ${ }^{55}$ in der Innen und Außen, das individuelle und das allgemeine Leben korrelierten. Die Kluft aber zwischen einer subjektiven Wirklichkeit des Individuums und der objektiven Realität beraubt den poetischen Gedanken seines Widerhalts in der realen Welt. Es ist die vielberufene moderne Krise der Dichtung, deren Ende als geschichtliche Notwendigkeit Hegel prognostiziert. Das Leiden an dieser Krisensituation ist das Stigma von Grillparzers Modernität. Es sei sein vergebliches Streben gewesen, sagt er, wieder "die Poesie dem Ursprünglichen [...] der alten Dichter näher zu bringen." Ohne historisierend und ästhetisierend der Gegenwart zu entfliehen. Poesie meint bei Grillparzer Verschiedenes, je nach dem Aspekt: Denk- oder Schreibweise, oder auch eine objektive Qualität der Realität. (So erscheint die bunte Ungleichzeitigkeit des Gleichzeitigen im Vielvölkerstaat poetischer als die Gleichschaltung des Nationalstaats). Unter den Bedingungen des Zeitalters der Prosa steht Poesie in Opposition zu seinen dominierenden Tendenzen. Im Gegensatz zur Vorherrschaft des abstrakten Denkens setzt sie das Bild, die konkrete Anschauung, die natürliche Empfindung als Mittlerin von Sinnlichkeit und Sinn. Die Poesie erscheint als Wahrerin der individuellen Erfahrung und des persönlichen und primären Weltbezugs ('eigentliche Gegenwart', 'real presence' im Sinne George Steiners, wider die Hypertrophie des Sekundären und Parasitären). Sie wird dadurch zum Anwalt des Humanen und der Würde des Menschen.

Sie wird dies kraft der Sprache. Grillparzer führt als Unterschied von Prosa und Poesie auch an, daß diese "die willkürlichen Zeichen zu natürlichen zu erheben" suche. Die Wirkung der im Vers transformierten kommunen Sprache ist Teil seiner Argumentation. Freilich, Grillparzer war kein genuiner Lyriker. Und die moderne Erneuerung der Poesie (gegen Hegels Verdikt) als 'poésie pure', emanzipiert von der Realität, hätte er sicher abgelehnt (so wie dies bei den romantischen Vorläufern der Fall war). Aber an dem Ungenügen und Unbehagen an der gegebenen Sprache als Grunderfahrung und Motor moderner Dichtung hatte er teil. Doch statt die verbrauchte und mißbrauchte Sprache in ihrer autonomen Entfaltung neu zu beseelen, wollte er der Sprache Substanz und Glaubhaftigkeit rückgewinnen durch ihre Bewährung in der Realität. Um den inflationös entwerteten Wörtern reale Deckung zu schaffen, suchte seine dramatische Kunst die Integration der Sprache in die Unmittelbarkeit der Szene. Wer diese Intention nicht erkennt, kann Grillparzer nicht verstehen. Die Kritik an Grillparzer setzt immer bei der Sprache ein. Sie sei glanzlos, mangelnd an schöpferischer Kraft,

55. G.W. Fr. Hegel, Werke Bd. 15, Vorlesungen über die Ästhetik III (Teil C. I. 2. C.) Frankfurt/M. 1970. S. 392. 
epigonal. Sprachmächtige Antipoden und Kontrahenten wie Karl Kraus und Friedrich Gundolf sind sich darin einig. Sie sehen an Grillparzers Wollen vorbei, und haben in ihrer ungebrochenen Sprachherrschaft kein Ohr für die Subtilität seiner Dramenverse. Iç bedaure sehr, hier nicht verweilen zu können.

Kein deutlicheres Indiz für Grillparzers Modernität als sein tiefverwurzeltes Mißtrauen gegenüber der Sprache. Nichts ist weniger kennzeichnend für den Epigonen. Was ihm zu schaffen macht, ist die Interferenz der konventionellen und künstlichen Sprache mit der Authentizität der natürlichen Empfindung. Er zerreißt ein tiefempfundenes Dankesschreiben, weil "jede gewählte Wendung" die Wahrheit des Gefühlten zu verfälschen und "herabzuziehen" schien. Er, der Schriftsteller konnte einem Brief anvertrauen: "Feder und Dinte sind mein entschiedenster Haß" und ein Brief habe für ihn "immer etwas ich möchte sagen Frevelhaftes", wie ein "Artefakt, wie ein Verrat an aufrichtiger, wahrer Empfindung", gegenüber der natürlichen Sprechsituation mit der begleitenden Sprache von "Blicke und Händedruck". ${ }^{56}$ Darum hat der Dramatiker Grillparzer die Sprache der Worte auf der Bühne eingebunden in die schaubare Szene. Darum belebt er die gehobene Sprache des Verses durch den Ductus der Umgangssprache und eine österreichische Kandenz.

Sein Mißtrauen gegen den selbstsicheren Umgang mit dem reichen Instrumentarium der verfügbaren Sprache ist Symptom einer Erbengeneration, der nach den Gipfelleistungen der deutschen Klassik die eigene Leistung problematisch erschien, der eigene Ausdruck eingeengt. Und es ist anderseits die österreichische Aversion gegen die Affektation und das rhetorische Übermaß der Schriftsprache. "Sie sind auf ihrem Theater an den prächtigen Wortschwall gewohnt; die Handlung mit unbedeckter Blöße ärgert ihr keusches Auge", notierte er 1828 in sein Tagebuch. ${ }^{57}$ Und ein andermal trotzig im regionalen Selbstbewußtsein: "Ich bin ein dorischer Dichter." ${ }^{\text {"58 }}$

Es kam ihm auf die Wahrheit der szenischen Darstellung an, ihre 'erweislose' Wirklichkeit. Dem ist die Sprache untergeordnet. Sie braucht Raum, um sich psychologisch überzeugend zu entfalten. So erscheint Heros Anfangsmonolog matt, und blüht auf im zauberhaften IV. Akt zu hoher poetischer Schönheit ("wenn dieser Akt gelingt, ist der Gewinn für die Poesie groß", notiert er in sein Tagebuch die intendierte dramatische Vergegenwärtigung eines Zustands). Das Studium der Varianten bezeugt Grillparzers bewußte Arbeit an seinem Stilideal. Ein besonders einprägsames Beispiel ist im Bruderzwist Kaiser Rudolfs Vision der beglückenden Planeten-Konjunktur, in der ersten Fassung in der Eloquenz von vierzehn prächtigen, strömenden Versen. In der endgültigen Fassung, um der

56. Briefe (28.1.1827). GW Bd. 4, S. 779 f.

57. Tgb. 1626 (1828). Ebd., S. 442.

58. Tgb. 1625 (1828). Ebd., S. 441. 
Situation des kränklichen, durch die Vision aufgewühlten alten Mannes zu entsprechen, auf sechs Verse verkürzt, das rhetorische Strömen gedämpft, zum Schluß die Syntax sich auflösend in Anakoluthe, übergehend in Verstummen und Gebärde. Szenenanweisung: "immer leiser sprechend. Er verstummt allmählich. Sein Haupt sinkt auf die Brust." - Für die psychologische Dimension von Grillparzers Dramen sind wir im Jahrhundert Freuds rezeptiver als seine Zeitgenossen es waren und sein konnten, mit unserem wacheren Sensorium für die Signale des Versprechens, der gebrochenen Rede, der Interferenz des Unbewußten in der verräterischen Gebärde; mit unserem an der modernen Literatur geschulten Sinn für Andeutungen, für Ambiguität und Ambivalenz.

Thematisch ist der bedeutsamste Aspekt von Grillparzers Modernität die im klassischen Rahmen wohl einzigartige Revision des Helden: durch Schwund von Pathos, bis zur Skurrilität und inneren Widerspruch (welch heldenhafter Antiheld ist dieser Bancban!); durch Selbstkritik vor allem und die Perspektive der Opfer. Was für Napoleon, nach der Aufzeichnung des jungen Grillparzer, nicht beachtete "Nebensache" war ("seine Gedanken, immer nur auf die Hauptsache ausgerichtet" $)^{59}$, erhielt in Grillparzers Geschichtsdramen höchstes Gewicht. König Ottokar muß erkennen:

Ich aber hab sie hin zu Tausenden geworfen

Um einer Torheit, eines Einfalls willen,

Wie man den Kehricht schüttet vor die Tür.

Unvergeßlich am Schluß der Jüdin von Toledo die Klage Esthers:

Sie sind die Großen, haben zum Versöhnungsfest

Ein Opfer sich geschlachtet aus den Kleinen

Und reichen sich die annoch blutge Hand.

"Mit der Stimme Esthers bezeugt der Autor, daß er das Opfer nicht an das Affirmationsbedürfnis der 'Großen' verrät." ${ }^{60}$ Die Klage der Schwester über den Tod Rahels ist eine Anklage, ein Ausbruch Grillparzers. Dieser Schluß übertönt die beiden anderen Schlüsse des Dramas, den des spanischen Staatstheaters und des jüdischen Satyrspiels, durch seine poetische Intensität. Der Reim, der in christlicher Versöhnung das Staatstheater beschließen soll, bleibt matt im Nachhall dieser Anklage. Max Kommerell schreibt:

59. Hier zitiert nach Hans Höller "Grillparzer und der Krieg". In: Literatur und Kritik 251/252, März 1991. S. 47-53.

60. Klaus Schuhmacher, Paragraphie. Über das gedichtete Recht. Stuttgart 1992. Siehe dort Kap. "Franz Grillparzers versagendes Umschreiben". Zitat S. 118. 
Der griechische Medeamythos ist erlebt mit dem Siegesgefühl des Kolonisators, der Grillparzers aus dem Schicksal der kolonisierten Schicht. ${ }^{61}$

Erlebt auch aus der Sicht der Frau, die zum Opfer des Mannes wird. Der Verrat des Mannes an der Frau ist ein Grundmuster von Grillparzers Dramen: Phaon und Sappho, Jason und Medea, Raimund und Melusina, auch Primislaus und Libussa, vor allem König Alfons und Rahel. Hans Höller hat in einem der anregendsten jüngsten Grillparzer-Aufsätze die Analogie zu Ingeborg Bachmann herausgearbeitet (Der 'Todesarten-Zyklus' des 19. Jahrhunderts. Ingeborg Bachmann und Franz Grillparzer; ${ }^{62}$ der heutige Text eine Art Optik für den in der geschichtlichen Vergangenheit weiter zurückliegenden). Diese Dominante Grillparzers ist von erheblichem aktuellen Interesse. Es ist bestimmend für das Grillparzer-Buch der amerikanischen Germanistin Dagmar C. G. Lorenz (Grillparzer. Dichter des sozialen Konflikts. Wien, Köln, 1986).

Der psychologische Tiefblick seiner Tagebücher in gnadenloser Introspektion ist von verblüffender Modernität. Darum erkannte Kafka Grillparzer als seinen "eigentlichen Blutsverwandten", gemeinsam mit Kleist, Dostojewski, Flaubert (in einem Brief an Felice; er nennt ihn an erster Stelle und bemerkt, nur Dostojewski in dieser Verwandtenreihe habe geheiratet).$^{63}$ Mit dem Blick tiefgehender Affinität sagt er von Grillparzer einmal: "er war lebendiges, abzutastendes Unglück."64 Beweise wahren Verstehens aus den 'anderen Zeiten' sind Grillparzer von sehr verschiedenen bedeutenden Repräsentanten zuteilgeworden. Von Hofmannsthals produktivem inneren Bezug eines gemeinsamen österreichischen Sensoriums reicht die Rezeptionsspanne zu Kafkas obsessiver Identifikation mit dem Zwiespältigen und Leidenden. Dem geistigen Außenseiter seiner Zeit öffneten sich Zugänge aus den 'anderen Zeiten'. Ein Jahr nach Grillparzers Tod erschien die erste von Nietzsches Unzeitgemäße[n] Betrachtungen. Nietzsche hat Grillparzers posthum erschienenen ästhetischen Studien sogleich gelesen. Er empfiehlt sie dem Freund Erwin Rohde mit dem Zusatz: "Er ist fast immer einer der Unsrigen."65 Auch Jacob Burckhardt hat in Basel gleichzeitig die posthume SauerGesamtausgabe erworben und schreibt am Silvesterabend 1872 in einem Brief an Friedrich von Preen:

61. Max Kommerell, vgl. Anm. 41, ebd., S. 92.

62. In: Jahrbuch der Grillparzergesellschaft. 3. Folge, Bd. 15 (1983). S. 141-153.

63. Franz Kafka, Briefe an Felice. Hrsg. von Erich Heller und Jürgen Bon. Frankfurt/M. 1967 (13. Tausend 1983). S. 277.

64. Brief an Grete Bloch, 12 Mai 1914. Ebd. S. 574.

65. Friedrich Nietzsche, Sämtliche Briefe. Kritische Studienausgabe Bd. 4, Mai 1872 - Dezember 1874. (Hier Brief vom 7.12.1872). München 1986. S. 98. 
Ich habe mir den ganzen Grillparzer angeschafft und bin aus Dramen, Selbstbiographie und Aufzeichnungen aller Art, die dieser Weltfluchtling hinterlassen mit Staunen innegeworden, wie nützlich und fruchtbar eine solche Zurückgezogenheit für die Nachwelt sein kann. ${ }^{66}$

In der Zweiten seiner Unzeitgemäße[n] Betrachtungen ('Vom Nutzen und Nachteil der Historie für das Leben') hat der junge Nietzsche Grillparzer als Kronzeugen seiner radikalen Zeitkritik aufgeführt und zustimmend zitiert. Der junge 'Unzeitgemäße' fand sich in seiner revolutionären und folgereichen Analyse einer allgemeinen, tiefsitzenden Denkhaltung von dem konservativen Altösterreicher bestätigt, Grillparzer, dem "beiseitestehende[n] und still betrachtende[n]", wie Nietzsche ihn nannte. ${ }^{67}$

Aber die Zeiten, die seiner Zeitkritik größeres Verständnis entgegenbringen, sind nicht die 'anderen Zeiten', auf die er seine Hoffnung gesetzt hatte. Unser Krisenbewußtsein ist geschärft durch die leibhafte Katastrophenerfahrung jenseits seines Vorstellungsvermögens, und unsere stets latente Katastrophenangst ist nur zu berechtigt. Die 'anderen Zeiten', in die Grillparzer zu gehen gehofft hatte, wären jene, die zur Rückkehr von einem Irrweg den Mut aufbrächten, die rücksichtslose Ichsucht überwunden hätten, die Wurzel allen Übels, um den Weg zu gehen, der der tiefsten Einsicht und Sehnsucht der Menschheit gemäß wäre. In der Richtung von Grillparzers Utopie:

Das Wissen und der Nutzen scheiden sich

Und nehmen das Gefühl zu sich als Drittes;

Und haben sich die Himmel dann verschlossen,

Die Erde steigt empor an ihren Platz,

Die Götter wohnen wieder in der Brust

Und Demut heißt ihr Oberer und Einer. ${ }^{68}$

66. Jacob Burckhardt, Briefe. Vollständige und kritische Ausgabe. Mit Benützung c handschriftlichen Nachlasses bearbeitet von Max Burckhardt. Basel 1963. Band V, S. 182.

67. Friedrich Nietzsche, Unzeitgemäße Betrachtungen II. Vom Nutzen und Nachteil der Historie für das Leben. Hier zitiert: Kritische Studienausgabe Bd. 1. Zweite, durchgesehene Ausgabe, München 1988. S. 277.

68. Libussa, Fünfter Aufzug (2484-2489). GW Bd. 2, S. $342 f$. 